\title{
Dynamic Consequences of the Emplacement of Kimberlite Dikes
}

\author{
Lionel Wilson ${ }^{1,2}$ and James W. Head III $^{2}$ \\ ${ }^{1}$ Environmental Science Dept., Lancaster University, Lancaster, U.K. \\ ${ }^{2}$ Department of Geological Sciences, Brown University, Providence 02912, U.S.A.
}

We argue that many of the unusual and enigmatic morphological properties of Class 1 kimberlite deposits (as defined by Field and Scott Smith, 1999; Skinner and Marsh, 2004) and the diatremes with which they are associated can be understood as the consequences of transient events that take place during the opening of a pathway from a deep mantle magma source to the surface (Wilson and Head, 2007). Subsequent events may modify the initial structures, especially if a prolonged eruption occurs after the initial transient opening (Sparks et al., 2006), but we infer that such changes cannot completely destroy the initially imposed morphology. The control on the events that we consider is the formation of a brittle fracture at unusually great depth in the mantle. This must be due to a combination of the large spatial scale and high rate of deformation of the rocks surrounding this magma source region. The underlying cause is as yet poorly understood but may be associated with deeper-seated processes (e.g., Sim and Agterberg, 2006). The key issues are that the resulting strain rate is large enough to drive the rheology of the source host rocks from plastic into elastic behavior, thus allowing a brittle fracture to form, and that once this process is initiated it is self-sustaining (Head and Wilson, 2008).

The rapid propagation speed of a brittle fracture leads to physical conditions within its upward-growing tip that are an extreme version of processes more often associated with shallow dikes in the crust, viz., the presence of a pocket of vapor at a very low pressure (Lister, 1990; Rubin, 1993), underlain by a region of magmatic foam (Wilson and Head, 2007). The absolute pressure in the vapor cavity is buffered by the saturation pressure of the most soluble volatile present in the magma, and is thus a function of the volatile species and the amount of this volatile present in the magma source region. The low pressure in the dike tip, coupled with the high pressure in the dike source, imposes a large pressure gradient on the melt in the dike and forces a high magma rise speed, especially in the early stages of dike growth.

In earlier work (Wilson and Head, 2007) we assumed that $\mathrm{CO}_{2}$ was the dominant magma volatile, but $\mathrm{H}_{2} \mathrm{O}$, if present, will lead to an even lower pressure in the propagating dike tip and even more extreme conditions. We illustrate these issues in Fig. 1, where we use dike tip pressures in the range 0.1 to $0.7 \mathrm{GPa}$, appropriate to the threshold of water exsolution in kimberlite magmas containing up to $\sim 10 \%$ water, covering the range of water contents summarized by
Sparks et al. (2006). Fig. 1 shows (a) the mean speed at which the opening dike tip propagates upward and (b) the time for the tip to reach the surface after the brittle fracture begin to propagate, as a function of the dike tip pressure for the case where the magma source depth is $200 \mathrm{~km}$. Fig. 2 shows the same quantities, mean speed and rise time, as a function of the magma source depth when the dike tip pressure is $0.2 \mathrm{GPa}$, corresponding to $\sim 4$ weight $\%$ water in the magma.

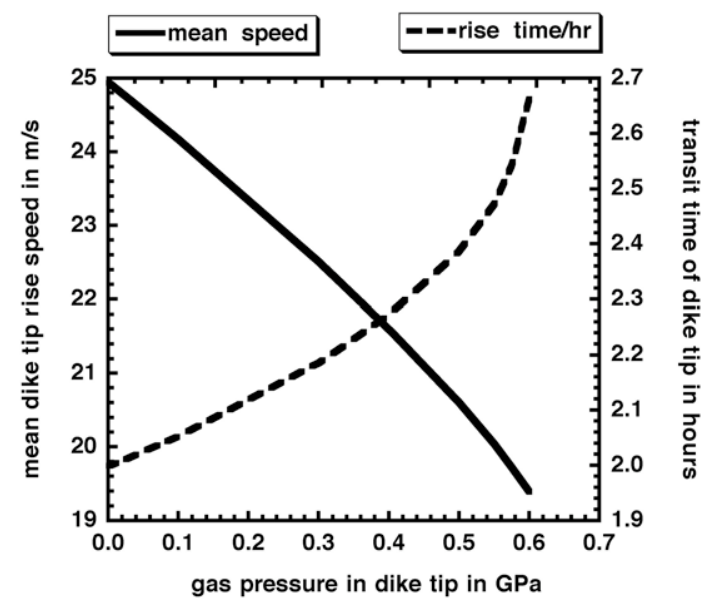

Fig. 1. Mean speed at which dike tip propagates upward and time for dike tip to reach surface from 200 $\mathrm{km}$ depth as a function of gas pressure in dike tip.

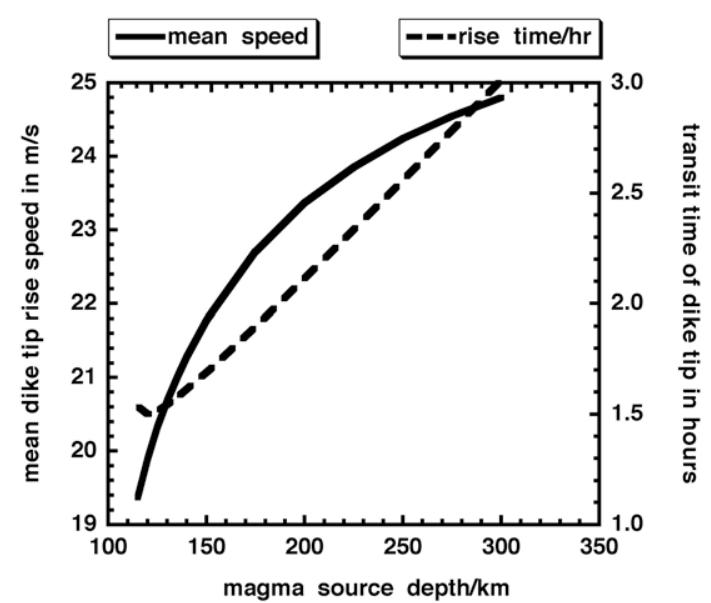

Fig. 2. Mean dike tip travel speed and rise time as a function of magma source depth when dike tip pressure is $0.2 \mathrm{GPa}$, corresponding to $\sim 4 \mathrm{wt} \%$ magma water.

Clearly, the high rise speed and short transit time of the dike tip are not very sensitive to either the source depth or the volatile content. 
Note that the dike tip rise time curve in Fig. 2 has an inflexion when the magma source depth is $\sim 120 \mathrm{~km}$. All of the illustrations in Figs. 1 and 2 assume a kimberlitic magma with a density of $2900 \mathrm{~kg} \mathrm{~m}^{-3}$ rising through a crust $50 \mathrm{~km}$ thick with a density of $2700 \mathrm{~kg}$ $\mathrm{m}^{-3}$ overlying a mantle with density $3400 \mathrm{~kg} \mathrm{~m}^{-3}$. With this combination of conditions, kimberlites originating at depths shallower than $\sim 110 \mathrm{~km}$ cannot reach the surface, because their positive buoyancy in the mantle does not compensate for their negative buoyancy in the crust. This is a common issue for all magmas traveling directly to the surface from mantle depths, but is particularly important for kimberlites because the high volatile contents mean that the dike tip pressures are higher than for more volatile-poor melts and hence the pressure difference acting over the column of magma in the dike (which must both support the magma weight and provide the work needed to overcome wall friction), is less. If a rapidly propagating dike were to stall as a result of these limitations, the pressure in its upper tip would rise (because no pressure gradient is now required to maintain the magma motion). This would cause a shrinkage of the gas bubbles trapped in the foam layer beneath the free gas pocket in the dike tip (see Fig. 2b in Wilson and Head, 2007) but would also allow time for these bubbles to rise and possibly collapse into the gas pocket. The resulting changes in stress distribution across the dike walls could lead to complex episodes of wall shattering and could also possibly lead to a renewed phase of upward dike propagation. However, this would not necessarily lead to the dike tip reaching the surface. The potential for forming complex intrusive structures in the crust clearly exists.

For a kimberlite dike just at the point of breaking through to the surface, Fig. 3 shows the difference between the absolute pressure of the magma inside the dike and the lithostatic load of the host rocks.

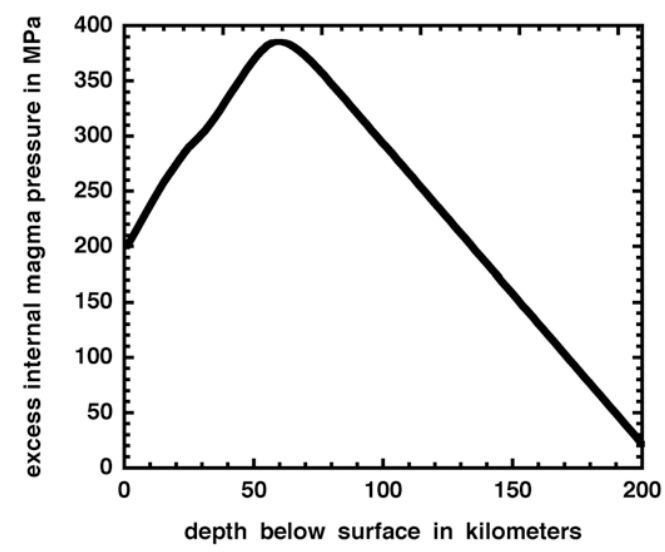

Fig. 3. Variation with depth below the surface of the difference between the magma pressure and the host rock lithostatic load in the case of a kimberlite dike on the point of breaking through the surface. This pressure acts to compress the wall rocks as the dike tip nears the surface. Abrupt relaxation of this pressure may induce wall rock shattering.
This large internal excess pressure acts to stress the dike wall rocks in compression and may cause fracturing. As soon as magma vents to the atmosphere, however, the pressure in the vent decreases to atmospheric extremely rapidly, and the absolute pressure decreases everywhere in the shallow part of the system. We argue (e.g., Wilson and Head, 2007) that it is this abrupt relaxation of the internal pressure that determines the morphological properties of diatremes.

\section{References}

Field, M., Scott Smith, B. 1999. Contrasting Geology and Near-Surface Emplacement of Kimberlite Pipes in Southern Africa and Canada. Proc. $7^{\text {th }}$ Int. Kimberlite Conf. 1, 214-237, J. Gurney, Ed. (Cape Town).

Head, J. W., Wilson, L., 2008. Integrated model for kimberlite ascent and eruption, 9th International Kimberlite Conference Extended Abstract No. 9IKCA-00284.

Lister, J. R., 1990. Buoyancy-driven fluid fracture: The effects of material toughness and of low-viscosity precursors. Journal of Fluid Mechanics, 210, 263280.

Rubin, A. M., 1993. Dikes vs. diapirs in viscoelastic rock. Earth Planet. Sci. Lett., 119, 641-659.

Sim, B.L., Agterberg, F.P., 2006. A conceptual model for kimberlite emplacement by solitary interfacial megawaves on the core mantle boundary. Journal of Geodynamics, 41, 451-461.

Skinner, E., Marsh, J., 2004. Distinct kimberlite pipe classes with contrasting eruption processes. Lithos, 76, 183200.

Sparks, R.S.J., Baker, L., Brown, R.J., Field, M., Schumacher, J., Stripp, G., Walters, A., 2006. Dynamical constraints on kimberlite volcanism. Journal of Volcanology and Geothermal Research, $155,18-48$.

Wilson, L., Head, J. W., 2003. Deep generation of magmatic gas on the Moon and implications for pyroclastic eruptions, Geophysical Research Letters 30. (12), 1605, doi: 10.1029/2002GL016082.

Wilson, L., Head, J.W., 2007. An integrated model of kimberlite ascent and eruption. Nature 447, (7140), 53-57, doi:10.1038/nature05692. 